\title{
Analysis of Pedagogical Considerations of M-Learning in Smart Devices
}

\author{
doi:10.3991/ijim.v3i4.855 \\ Ali Mostakhdemin-Hosseini \\ Helsinki University of Technology, ESPOO, Finland
}

\begin{abstract}
Unlike the traditional classroom based learning where the learning happened on the specific time and place. In mobile learning the learning is not depended to any designated time and place. Learning through mobile device requires extensive design and pedagogical considerations. The traditional teaching pedagogy theories are not suitable for mobile learning since the main assumptions on teaching are in the classroom. There have already been some initiatives for defining distinct pedagogical theories for mobile learning. The main focuses of the mobile learning pedagogical consideration must be directed to content of the learning materials and the context where the learning occurs.
\end{abstract}

Index Terms-Pedagogy, mobile learning, content

\section{INTRODUCTION}

\section{Definition of mobile device:}

Mobile device is a portable device that uses wireless technology to transmit and exchange data. Based on Winn [12] mobile device are capable to

1. Get information to people whenever it is needed

2. Getting people to information

Base on the mobile device definition places are no more constrains

\section{Definition of learning:}

The learning is cognitive process or knowledge. The natural world and the formal schooling training are the main learning environments which we encounter. Technology can make use of mobile within and between these two environments [12]

\section{Definition of Pedagogy:}

The Oxford pocket dictionary of current English defined pedagogy as the method and practice of teaching, esp. as an academic subject or theoretical concept: the relationship between applied linguistics and language pedagogy.

Traditional classroom learning has already well defined pedagogical principles e.g. Chickering and Gamson [1] recommend 7 principles for good practice of undergraduate education.

- Encourages students - faculty contact.

- Encourages cooperation between students

- Encourages active learning

- Give prompt feedback

- Emphasises time on task

- Communicates high expectations

- Respects diverse talents and ways of learning.
These principal also apply to e-learning and m-learning. As Keeton [2] defined set of principle for e-learning pedagogy e.g. use extensive and deliberate practise, provide prompt and extensive feedback and develop learners' effectiveness as learners early in their education.

Unlike m-learning e-learning is nowadays often directed by pedagogy. The e-learning pedagogy extended with new principles defined specifically for e-learning e.g. Keeton [2] defines the following criteria for pedagogies extends.

- Make learning goals clear

- Use extensive and deliberate practise

- Provide prompt and extensive feedback

- Provide an optimal balance of challenge and support tailored to the individual student's readiness and potential.

- Elicit active and critical reflection by learners on their growing experience base.

- Link inquiries to genuine problems or issue of high interest to the learners.

- Develop learners effectiveness as learners early in their education

- Create an institutional environment that supports and encourages inquiry.

So far the pedagogical researches in mobile learning were mainly based on the e-learning pedagogical considerations. At early stage of mobile learning utilization it's being considered as an enhanced to the existing e-learning system [10]. The content of e-learning platform is transferred to mobile devices. However even though elearning platform has been utilized for many years by education institutes still there have not been researches on pedagogical effectiveness of the learning experience by elearning.

The pedagogical researches on mobile learning as an independent or enhanced learning tool in education process are relatively new. Waycott [3] investigates how efficient mobile devices are as tool in supporting the learning based on studying activity theory. These findings suggest that the integration of a new tool into existing activities is two-way process. The new tools introduce new possibilities and constraints to the activity. Ellen [4] concentrates to the design of the mobile learning and the learning needs of connected people. Basically mobile learning is not similar to the e-learning and it is not focused just to the mobile phones which are always connected.

Seppälä [5] studied the convenience and expediency of mobile learning and the mobile learning pedagogies importance and concludes that there are a lot of pedagogical 
potential in mobile learning which require practical testing and further research.

\section{Mobile Learning Pedagogy}

M-learning has started to emerge as potential educational environments and supporting tool in education process. These devices have been utilized to promote individual and collaboration among students in their education activities. The mobile devices such as mobile phones are well advanced nowadays which provide opportunity for education institutes to enhanced tool. In additions research [8] shows mobile devices penetrations among students and staff in Finland is on maximum level. But utilizing m-learning as an enhanced tool suffers from several factors such as theory of mobile learning pedagogy. There have been many attempts to feel this gap. Some of the most recent initiatives are reveals as follows:

Taylor [6] has a case studied on task-centred approach to evaluate a mobile learning environment for pedagogical and identified and argued the learning opportunities presented by the new mobile technology, the potential impact of the way people learning tasks. And Chen [7] also argued that m-learning brings additional considerations to the basic principals of the pedagogical which are as followed: urgency of learning need, initiative of knowledge acquisition, mobility of learning setting, interactivity of learning process, stiltedness of instructional activities and integration of instruction content. Unlike the traditional classroom base learning where the learning happened on the specific time and place. In m-learning the learning happened out of any designed time and place. Ktoridou [9] argues that there is need for pedagogy for mobile learning that will provide the scientific basis for networked and collaborative learning. And it must accommodate different teacher - and learner perspectives, promote learner-centered environments and collaboration among learners and between learners and educator.

It is essential to have well defined principles of $\mathrm{m}$ learning pedagogy. These principles assist to utilize the mobile learning effectively to the education process. Without pedagogy principles mobile devices are not fully utilizable as independent learning tool where the learning carries out only through mobile devices.

\section{CONCLUSION}

Recent advancements in mobile devices and wireless technologies have enabled to utilize mobile devices in educational institutes as an enhanced tool. Researches e.g. [11] indicate that students and staff are very satisfied with the new wireless technology in education process. Usability and pedagogical factors play important role in Mlearning platforms. Mobile pedagogy is complex process with compare to the counterpart in e-learning or traditional classroom. Complexity in mobile devices and mobile content required extensive pedagogical considerations. However the lack of mobile learning pedagogy was not the showstopper for universities and educational institutes to utilize this device in educational process. Pedagogy factors are however considered as key factors for learning productivity.

It is essential that the content for learner on mobile devices must be organized and design based on the device features. The traditional pedagogical roles are not necessary suited for the mobile device. The mobile learning pedagogy is premature and requires extensive studies. There have been many initiatives in recent years but not enough to have a pedagogy theory for mobile learning.

\section{REFERENCES}

[1] W.J. Book, Modelling design and control of flexible manipulator arms. A tutorial review, Proc. $29^{\text {th }}$ IEEE Conf. on Decision and Control, San Francisco, CA, 1990, 500-506).

[2] Keeton M.T. (2004) Best online instructional practices: Report of phase 1 of ongoing study. Journal of Asynchronous Learning Networks, 75-100

[3] Waycott, j (2001), An Investigation into the Use of Mobile Computing Devices as Tools for supporting learning and worksplace Activities.

[4] Ellen D. Wagner, "Enabling Mobile Learning, EDUCAUSE Review, vol. 40, no. 3 May/June 2005 pp.40-53"

[5] Seppälä, Pauliina Alamäki Harri (2002), Mobile learning and Mibility in Teacher Training, http://ieeexplore.ieee.org/iel5/8056/ 22273/01039235.pdf

[6] Josie Taylor, A (2003) Task-centred Approach to Evaluating a Mobile Learning Environment for Pedagogical Soundness, 2003 http://kn.open.ac.uk/public/document.cfm?documentid=3102

[7] Chen, Y-S., T.-Ch. \& Sheu, J,-p. (2003). A mobile learning system for scaffolding bird watching learning, In Journal of Computer Assisted Learning, No. 19, pp 347-359 (doi:10.1046/j.02664909.2003.00036.x)

[8] Mostakhdemin-Hosseini Ali, Najafabadi Nagmeh(2006) "The Mobile Phone Constitutive Effect on Student Life in Finland" IEEE-IMCL, Interactive Mobile \& Computer Aided Learning 1921 April 2006, Amman-Jordan.

[9] Depo Ktoridou, Nikleia Eteokleous, Adaptive m-learning: Technological and Pedagogical aspects to be considered in Cyprus tertiary education. Recent Research Developments in Learning Technologies (2005)

[10] Mostakhdemin-Hosseini Ali, Tuimala Jarno (2005). Mobile Learning Framework. Proceedings IADIS International Conference Mobile Learing 2005, Malta, pp 203-207.

[11] Mostakhdemin-Hosseini Ali, Mustajärvi, Jari (2005). "Evaluation of Mobile Learning System Prototype" International association for development of Information Society, IADIS February $23-25^{\text {th }}$, 2005, Algarve, Portugal

[12] Winn William, (2005) KEYNOTE LECTURES, What is Mobile Learning and How Do We Make It Effective, IADIS International Conference, Mobile Learning 2005, 28-30 June, Qawra, Malta

\section{AUTHORS}

Ali. Mostakhdemin-Hossieni is a researcher at Helsinki University of Technology and senior lecturer at HAMK Applied Science University, Forssa, Finland (amir@cc.hut.fi).

Submitted 24 February 2009. Published as resubmitted by the authors on 9 October 2009. 